\title{
Article
}

\section{Referent selection in children with Autism Spectrum Condition and intellectual disabilities: Do social cues affect word-to-object or word-to-location mappings?}

Field, Charlotte, Lewis, Charlie and Allen, Melissa

Available at http://clok.uclan.ac.uk/28990/

Field, Charlotte ORCID: 0000-0001-5155-0406, Lewis, Charlie and Allen, Melissa (2019) Referent selection in children with Autism Spectrum Condition and intellectual disabilities: Do social cues affect word-to-object or word-tolocation mappings? Research in Developmental Disabilities, 91 . p. 103425. ISSN 0891-4222

It is advisable to refer to the publisher's version if you intend to cite from the work. http://dx.doi.org/10.1016/j.ridd.2019.05.004

For more information about UCLan's research in this area go to

http://www.uclan.ac.uk/researchgroups/ and search for < name of research Group>.

For information about Research generally at UCLan please go to http://www.uclan.ac.uk/research/

All outputs in CLoK are protected by Intellectual Property Rights law, including Copyright law. Copyright, IPR and Moral Rights for the works on this site are retained by the individual authors and/or other copyright owners. Terms and conditions for use of this material are defined in the policies page. 



\begin{abstract}
Background - There is conflicting evidence regarding whether children with Autism Spectrum Condition (ASC) and intellectual disabilities (ID) follow social pragmatic cues such as a speaker's eye gaze or pointing towards a novel object to assist mapping a new word onto a new object (e.g. fast mapping).
\end{abstract}

Aims - We test fast mapping from a speaker's gaze and pointing towards objects in children with ASC and ID with varying chronological and receptive language ages compared with receptive language matched groups of typically developing (TD) children.

Methods and Procedure - Across eight trials, a speaker gazed and/or pointed towards one out of two objects while saying a new word. Pointing was either 'referential' (with intention), or 'incidental' (without obvious intention). To investigate whether children formed more robust word-to-object links rather than associative word-to-location ones, we reversed the original location of the objects in half of the test trials.

Outcomes and Results - Children with ASC were as successful as TD children using social cues to form word-to-object mappings. Surprisingly, children with ID did not fast map from referential pointing, or when objects changed location.

Conclusions and Implications - Children with ID may use different processes to facilitate word learning compared to TD children and even children with ASC.

Key words: Social Pragmatics; Gaze; Pointing; Autism Spectrum Condition; Intellectual Disability; Spatio-temporal position 


\section{What this Paper Adds}

This paper makes a valuable contribution to the research literature in several ways. Firstly, it investigates fast mapping from social pragmatic cues in three different populations (TD, ASC, ID) enabling exploration of whether any difficulties observed are due to ASC or cognitive impairments. There is controversy within the current literature about whether children with ASC can fast map from gaze and the age at which this ability develops. Thus, this study informs the current debate by recruiting children with ASC across different chronological ages (CA) and receptive language ages (RLA). We also investigate the function of pointing; exploring both referential and 'incidental' usage of the cue, in order to see if children still fast map when pointing is made to look incidental. Finally, the paper examines whether word object mappings are fragile or persist when the object changes location. The findings suggest that children with $I D$, rather than ASC, are impaired fast mapping from social pragmatic cues.

\section{Highlights}

- This study involved a speaker gazing and/or pointing at a novel object

- Children with Autism Spectrum Condition encode object names from gaze and pointing

- For gaze, this ability relates to chronological age

- Children with intellectual disabilities do not fast map from 'referential pointing'

- Object positioning affects fast mapping in children with intellectual disabilities 


\section{Referent selection in children with Autism Spectrum Condition and Intellectual}

\section{Disabilities: Do social cues affect word-to-object or word-to-location mappings?}

From early infancy, typically developing (TD) children are sensitive to social pragmatic cues (Beier \& Spelke, 2012). Speakers often gaze and/or point towards novel objects before naming them (Griffin \& Bock, 2000), leading TD children to understand that new words refer to new artefacts by as early as eighteen-months (Baldwin, 1991; 1993; Bloom, 2000; Hollich et al., 2000; Yale \& Mundy, 1998). Social cues help support joint attention, where speaker and child share focus towards a particular object (Tomasello, 1995).

There is controversy within the research literature regarding joint attention ability in children with Autism Spectrum Condition (ASC) ${ }^{1}$ and intellectual disabilities (ID) but without ASC. In the case of ASC, notable difficulties in intention monitoring (D'Entremont \& Yazbek, 2007; Somagyi, Kiraly, Gergely, \& Nadel, 2013) and social interaction (Stone, Ousley, Yoder, Hogan \& Hepburn, 1997) are linked to failure using social cues for referent selection $^{2}$ (Baron-Cohen, Baldwin \& Crowson, 1997; Preissler \& Carey, 2005). Individuals with ASC have particular difficulties attending to and understanding gaze (e.g. Congiu, Fadda, Doneddu, \& Striano, 2016; Jones, Carr \& Klin, 2008; Riby, Hancock, Jones \& Hanley, 2013). In studies where children hear a new word as they are looking at one object while a speaker looks at another, children with ASC have either relied upon their own gaze or inconsistently mapped words to referents (Baron-Cohen et al., 1997; Preissler \& Carey, 2005), suggesting a fundamental impairment using a speaker's gaze as a referential cue.

\footnotetext{
${ }^{1}$ The term Autism Spectrum Condition is used throughout rather than Autism Spectrum Disorder because the term 'disorder' is sometimes perceived as derogatory, whereas 'condition' highlights both strengths and weaknesses (Baron-Cohen, 2000; Kenny et al., 2015).

${ }^{2}$ It is important to distinguish between retention (e.g. 'slow mapping') and referent selection (e.g. 'fast mapping') (Horst, Scott, \& Pollard, 2010; McMurray, Horst, \& Samuelson, 2012). Some theorists argue that word learning only occurs when children demonstrate solid word-referent understanding after a delay, suggesting encoding of the word into long term memory (Capone \& McGregor, 2005; McMurray et al., 2012). Fast mapping, investigated here, requires children to make an initial referent selection emerging in the moment and is a related but separable component of longer-term word learning (Horst, McMurray, \& Samuelson, 2006).
} 
However, more recent studies suggest that children with ASC form word-object mappings (Akechi et al., 2011; Ellawadi \& McGregor, 2016; Luyster \& Lord, 2009; McGregor et al., 2013; Norbury, Griffiths \& Nation, 2010) from gaze, particularly when combined with pointing (Akechi et al., 2013). This suggests that some children with ASC may be attuned to social cues, helping them disambiguate referential ambiguity.

Although the evidence regarding whether children with ASC fast map from gaze is conflicting, they have a better understanding of pointing (Akechi et al., 2013; Travis \& Sigman, 2001). However, they may comprehend this via unusual mechanisms. From ninemonths, TD infants understand the communicative nature of pointing (Krehm, Onishi \& Vouloumanos, 2014). Thirteen-month-olds understand that speakers point towards objects as they name them (Gliga \& Csibra, 2009) and two-year-olds learn words for objects that speakers point towards (Kalagher \& Yu, 2006). TD infants (1-2 years) chose the correct container for a hidden toy when the experimenter ostensively gazed (repeatedly turned her head from the container back to the child) or both gazed and pointed (Behne, Carpenter \& Tomasello, 2005). When gaze is 'absent-minded' (glancing at the container with a distracted facial expression) and pointing 'distracted' (looking at her hand instead of the child), children choose at chance between the target and distractor container.

This suggests that referential intent underlies TD children's understanding of pointing. Indeed, TD children point both to request objects (protoimperative pointing) and to share enjoyment in objects with others (Tomasello, Carpenter \& Liszkowski, 2007). In contrast, the process by which children with ASC use and interpret pointing might be through association, simply pairing stimuli in the environment, rather than understanding referential intent (e.g. Samuelson \& Smith, 1998). They point to request an object, but show a reduced tendency for protodeclarative communication (Baron-Cohen, 1989; Mundy, 1995). Such pointing to share interest and enjoyment in an object may also be delayed (Camaioni, 
Perucchini, Muratori \& Milone, 1997), occurring less frequently than observed by TD toddlers (Baron-Cohen, 1989). Thus, children with ASC may use pointing simply to meet their needs, without understanding its broader social context. Comparing learning from a situation where pointing can be construed as a direct, social act to one where it can be interpreted as accidental can help tease these explanations apart.

Referent selection from social pragmatics has been neglected with regards to ID. As these individuals do not possess the characteristic social difficulties of those with ASC (e.g. Brereton, Tonge \& Einfeld, 2006; Wilkins \& Matson, 2009), it may be expected that they fast map from gaze and pointing. Supporting this assumption, children with developmental delay follow the pointing of others at an earlier mental age (MA) than those with ASC (Mundy, Sigman \& Kasari, 1994) and participants with learning difficulties point more to their own bodies than those with ASC when suggesting where someone should place a sticker, suggesting intact self-other relations (Hobson \& Meyer, 2005).

In terms of fast mapping, children with ID form a word-picture mapping following initial object exposure, although they are impaired relative to a TD group remembering the object name when faced with distractor objects or labels (Wilkinson, 2007). Furthermore, children with Fragile X (McDuffie, Kover, Hagerman \& Abbeduto, 2013) and Down Syndrome (McDuffie, Sindberg, Hesketh \& Chapman, 2007) fast map labels to novel objects. Children with Down Syndrome even retain novel words after a one-week delay (Sakhon, Edwards, Luongo, Murphy \& Edgin, 2018). Taken together, this suggests that children with ID without ASC may show better fast mapping ability than those with ASC.

However, there is also evidence to the contrary. Individuals with ID, by definition, have cognitive impairment, often including a delay in language and sometimes social interaction difficulties (Marrus \& Hall, 2017). Infants with developmental disabilities show a lack of gaze to and from objects and caregiver during a free play activity (Arens, Cress \& 
Marvin, 2005). This indicates that children with ID, like children with ASC, might struggle to fast map from gaze and pointing. Taken together, the research literature suggests that children with ID may have a better understanding of social pragmatics than children with ASC (Hobson \& Meyer, 2005; Mundy et al., 1994), but still experience difficulties relative to TD peers (Arens et al., 2005; Marrus \& Hall, 2017). Differences in terms of the chronological age (CA) and receptive language age (RLA) of participants with ASC and ID might explain why some studies have found success at understanding gaze while others have not. Children who have an older CA and/or RLA might be more likely to fast map from gaze. For example, due to more experience with these types of fast mapping situations (e.g. speaker gazing at an object at the same time as they label it). Better verbal ability is linked with understanding gaze in ASC (e.g. Falck-Ytter, Fernell, Hedvall, Hofsten \& Gillberg, 2012; Mcduffie, Yoder \& Stone, 2006; Mcgregor et al., 2013).

Studies reporting success in fast mapping tasks generally include children with higher RLA and/or RLA commensurate with CA (For example, in Akechi et al., 2011, children with ASC had a CA of 9 and RLA of 8; in Akechi et al., 2013 children with ASC had a CA and RLA of 8). In contrast, participants who did not succeed in Baron-Cohen et al., (1997) and Preissler and Carey (2005) had mean expressive and RLAs of two-year-olds with substantially older CAs ( 9 and 7 years, respectively). Furthermore, MA is positively correlated with language in children with ID (Ratner, 2005; Rosenberg \& Abbeduto, 1993). Individuals with ID who were found to have better social skills in Brereton et al., (2006) and Wilkins and Matson (2009), were relatively older (4-14 years and adulthood respectively), compared to Arens et al. (2005), who studied gaze behaviour in 9-25 month-old infants. Given that children with ASC have, however, been reported to use gaze in referent selection tasks as early as 30-months (Luyster \& Lord, 2009), recruiting participants of different levels of CA and RLA is necessary to test whether verbal ability facilitates fast mapping from gaze. 
To map words successfully, one must encode word-referent links, independent of environmental or social cues. For instance, TD infants notice object positioning (Canfield \& Haith, 1991; Johnson \& Tucker, 1996), learning words for stimuli with predictable rather than varied locations (Benitez \& Smith, 2012) and prioritise goal directed action over consistent object location (Moore, 1999; Woodward \& Guajardo, 2002). After originally viewing a hand grasping a toy, infants looked longer when the hand later reached in the same location for a different object than a different location for the same object (Woodward, 1998). This ability (forming word-to-object rather than word-to-location mappings) is useful as spatio-temporal location is less relevant for naming because objects are rarely fixed in terms of location.

Context may play a different role for children with ASC, who might instead encode more superficial properties such as consistency between location and object. Such associative learning would predict word-mapping errors (Baron-Cohen et al., 1997). These individuals might be more attracted to lower-level perceptual characteristics like object shape and colour (Hartley \& Allen, 2014) using this as a basis for learning rather than forming conceptual links. This might be linked to a local perceptual bias, which has been shown in children with ASC; notably, children with ID instead have global bias (Porter \& Coltheart, 2006). Therefore, we expect overall difficulties in fast mapping from gaze and when the object changes location between encoding and test trials in children with ASC, relative to their TD and ID peers.

The broad aim of this study is to investigate referent selection from social cues in three distinct groups of children (ASC, ID, TD) matched in terms of overall mean RLA. We test three hypotheses. First, we investigate fast mapping from gaze and pointing. We hypothesise that the TD children will perform the best, followed by the children with ID. In line with past research (Akechi et al., 2011; 2013; Norbury et al., 2010; Ratner, 2005; 
Rosenberg \& Abbeduto, 1993), we predict that CA and RLA will be positively related with fast mapping, with RLA expected to be more important than CA (Bani-Hani, Gonzalez Barrero, \& Nadig 2012; Ellawadi \& Mcgregor, 2016; Parish-Morris, Hennon, Hirsh-Pasek, Golinkoff \& Tager-Flusberg, 2007).

Secondly, we explore children's understanding of pointing. We expect participants with ASC who are able to fast map will fail to distinguish between 'referential' vs. 'incidental' pointing (where the speaker directs their gaze into the distance, as though momentarily distracted). In contrast, TD children and children with ID will only fast map from referential pointing, understanding that incidental pointing is accidental.

Finally, we anticipate that children with ASC and ID will find word-to-object mappings more difficult than word-to-location. However, TD children will be equally successful at both, retaining the mapping across spatio-temporal location. Taken together, our results will inform the use of social cues for referential disambiguation across atypical and typical development.

\section{Method}

\subsection{Participants}

Seventy-eight children (TD, $N=30$ : ASC, $N=27$ : ID, $N=21$ ) were recruited from 9 specialist schools, 2 mainstream schools and 2 day nurseries and tested in North West England. Fifty-five were male (18 TD, 23 ASC, 14 ID) and 23 were female (12 TD, 4 ASC, 7 ID). The three groups were matched on overall mean RLA. X University Research Ethics Committee approved the research and the children's parents gave informed written consent for their child's participation. See Table 1 for the participant details.

All children with ASC and ID previously received a clinical diagnosis by a qualified educational or clinical psychologist, using standardised instruments (e.g. Autism Diagnostic 
Observation Scale and Autism Diagnostic Interview - Revised: Lord, Rutter, DiLavore \& Risi, 2002; Lord, Rutter \& Le Couteur, 1994) and expert clinical judgment. All children with ASC had been diagnosed with autism, with three participants having co-morbid intellectual disabilities.

The children with ID had various developmental disabilities including Down Syndrome and rarer chromosomal disorders. The majority were identified as having learning difficulties or developmental delay. This matches epidemiological findings that approximately $50 \%$ (range in large samples 20-81\%) of children diagnosed with ID have no known etiology (Moog, 2005).

\subsection{Cognitive Tests}

Children were administered the British Picture Vocabulary Scale - Second Edition (BPVS-II; Dunn, Dunn, Whetton \& Burley, 1997) in order to ascertain RLA. The BPVS is often used for this purpose in studies with children with ASC (e.g. Allen, Hartley \& Cain, 2015; Gillespie-Smith, Doherty-Sneddon, Hancock \& Riby, 2014; Gillespie-Smith, Riby, Hancock \& Doherty-Sneddon, 2014) as it does not require written or oral responses, and is thus appropriate for individuals with communication impairment. We administered the Raven's Progressive Matrices (Raven, 2003) to assess children's non-verbal reasoning (minimum raw score 0, maximum 36). Children with ASC and ID were matched in CA, although the TD children were younger (both $p<.001$ ), due to the delayed mental age often observed in ASC and in keeping with various past literature (e.g. Hartley \& Fisher, 2018; Riguet, Taylor, Benaroya \& Klein, 1984; Sally \& Hill, 2006). The three groups had equivalent RLAs (all $p>.05$ ). Consistent with past research finding superior Raven's performance in ASC (Hayashi, Kato, Igarashi \& Kashima, 2007; Soulières et al., 2009), children with ASC had higher Raven's scores than the two comparison groups $(p<.05)$. 


\subsection{CARS and SCQ scales}

For most children, a parent or teacher completed the Childhood Autism Rating Scale (CARS; Schopler, Reichler \& Rochen Renner, 1988) (17 TD, 20 ASC, 14 ID) and the lifetime version of the Social Communication Questionnaire (SCQ; Rutter, Bailey, Berument, Lord \& Pickles, 2003) (17 TD, 18 ASC, 15 ID) to confirm or rule out ASC. All TD children scored well below the clinical threshold for ASC on both the CARS (30) and SCQ (15). The vast majority of children with ASC and ID scored according to their diagnostic category on both scales, with only one child (ASC) not scoring according to his diagnosis on both scales. Removing this data led to almost identical results, thus data were included in the study.

\subsection{Materials}

Children watched a video consisting of eight trials: two blocked trials of four different cue types (gaze, referential pointing, incidental pointing, and gaze + pointing) (see Figure 1 for an example gaze + pointing trial). Each trial showed a speaker seated at a table covered with a white tablecloth. Novel objects (created from unusual and/or adapted household equipment) were later superimposed onto the video, using iMovie. In each trial, two novel objects were positioned in front of the speaker, one to his left and one to his right. Different novel objects were used in each trial. For counterbalancing purposes (see procedure section), four different versions of the videos were used. The videos were edited and transferred onto a laptop computer. Participants with parental and school consent $(N=27)$ were filmed.

\subsection{Procedure}


Table 2 shows the study procedure and the differences between the cue types. Testing was conducted in a quiet area of children's school or day nursery. This was usually one-toone with the experimenter. In some cases, a member of teaching staff was also present, who watched but avoided intervening. Children were told that they would view a series of videos where a new object would be named and that their task was to choose which object had been named. On the video, the set-up of each scene was virtually identical, except for cue type. In this within-subjects design, each participant saw eight videos consisting of four different cue types (gaze, referential pointing, incidental pointing, gaze + pointing). Each cue type had one test trial with objects in the same position and one test trial with objects in the reversed position. Each scene showed an actor seated in front of a table with two novel objects positioned to his left and right, respectively (see Figure 1). He gazed/pointed/both gazed and pointed at one of the objects concurrent with uttering a novel label (e.g. "It's a modi").

Immediately following this, the actor segment ended and only the two objects appeared on screen. The experimenter asked the child to indicate (by pointing or an unambiguous verbal response) the previously named object (e.g. 'Show me a modi'). Task order, novel word use, and position of the target object were counterbalanced. Due to technical issues, one child with ASC and one child with ID did not complete the referential pointing trial where the positioning of the objects changed between encoding and the test trial ('reversed referential pointing') and one child with ASC did not complete the 'reversed incidental pointing' trial.

\section{Results}

Because three participants failed to complete all trials, children's responses were summed over trials and converted into proportions per trial type, yielding separate overall proportions for gaze, referential pointing, incidental pointing and gaze + pointing. As the two 
general ability measures (BPVS and Raven's) were highly correlated $(\mathrm{r}=.68, p<.001)$, and most analyses focus upon the relation between language and performance on pragmatic cues, the BPVS (RLA) was used in the following analyses (following Keppel \& Wickens, 2004) as a continuous covariate.

\subsection{Overall performance (accuracy) and preparation of data for further analyses}

Having checked the variance in each measure across groups ${ }^{3}$, we conducted a GLM analysis of the four types of trial (gaze, referential pointing, incidental pointing and gaze + pointing) as a repeated measure, with group as a factor and RLA as a continuous covariate. We centred the scores for RLA to guard against data breaching the assumption of homogeneity of regression slopes. The effect of Group was significant $(F(2,73)=3.14, p=$ $\left..049, \eta p^{2}=.08\right)$. A Bonferroni corrected pairwise comparison $(p=.047)$ showed that the ID group (77\% accurate) scored lower than TD participants (86\% accurate). The children with $\operatorname{ASC}(84 \%$ accurate) were not significantly different from either group. $\operatorname{RLA}(F(1,73)=$ $2.86, p=.095)$ and Trial $(F(3,219)=1.55, p=.23)$ were not significant. However, the Group $\times$ Trial $\left(F(6,219)=2.27, p=.037, \eta p^{2}=.06\right)$ and $\operatorname{RLA} \times \operatorname{Trial}(F(3,219)=5.08, p=.002$, $\left.\eta p^{2}=.07\right)$ interactions were significant.

In the following brief sections, we present analyses for each of the three hypotheses separately. A series of tests against chance are reported. Figure 2 depicts the results for the different trial types (broken down by group). Although there was good performance throughout, no group was at ceiling. On each measure, scores were within normal limits. We then present the follow up investigations of group by centred RLA and the third analyses in which we regressed each measure within each group by CA.

\footnotetext{
${ }^{3}$ For 'incidental pointing' and 'gaze + pointing', group distributions were slightly different; in each case the children with ID showed more errors than the TD and ASC children. As recoding each into a new binary variable followed by logistic regression produced similar results to analyses in which homogeneity was assumed, we proceeded with the general linear models reported here.
} 


\subsection{Hypothesis 1: Fast mapping from gaze and referential pointing.}

The one-sample t-tests revealed all three groups selected the object that the actor looked at $(p<.005)$ for gaze. The GLM revealed a significant main effect of $\operatorname{RLA}(F(1,72)=$ $\left.6.69, p=.01, \eta p^{2}=.08\right)$, but no other effects. When we regressed gaze scores onto CA we found no effects for the TD and ID samples, but clear positive relation in the children with ASC (intercept $=.14, \operatorname{Beta}=.43\left(F(1,25)=5.55, p=.03, \mathrm{R}^{2}=.15\right){ }^{4}$

For referential pointing, both the TD and ASC groups (both $p<.001$ ) but not the ID group selected the target object above chance (see Figure 2). The GLM revealed a main effect of Group $\left(F(2,72)=4.25, p=.02, \eta p^{2}=.11\right)$. Tukey tests (with the Tukey-Kramer formula here and throughout) showed that children with ID performed significantly lower than both the ASC $(p=.02)$ and TD $(p=.01)$ groups. Follow up regressions showed that CA did not influence performance in any group.

Figure 2 shows above chance responses in all three groups for gaze + pointing, but less accurate performance in children with ID. The statistical analysis confirmed this, with a main effect for both Group $\left(F(2,72)=5.18, p=.008, \eta p^{2}=.13\right)$ and a higher RLA indicative of success $\left(F(1,72)=5.75, p=.005, \eta p^{2}=.14\right)$. Tukey tests showed worse performance in the ID children than the two other groups (in both cases $p<.02$ ). There was no Group $\times$ RLA interaction nor any effects of CA in the regressions on each group's performance.

\subsection{Hypothesis 2: Fast mapping from Incidental Pointing}

\footnotetext{
${ }^{4}$ Children may fail to form word-object mappings from gaze due to either not noticing it or noticing it but then not realizing its significance. In order to see which occurred here, we reviewed the videos where parents and teachers had consented for filming. Over 54 trials for twenty-seven participants, there were only two trials (1 TD, 1 ASC) where the child failed to look at the speaker's face at the time he first spoke and gazed at the object. All three groups looked at the speaker's face as he gazed towards the object: significantly above chance $(p<.001)$. A one-way (Group) ANOVA found no group differences. Therefore, the positive relationship between CA and performance on the gaze trials for children with ASC could not be attributed to those with a lower CA not noticing the cue.
} 
All three groups chose the object the speaker pointed to at a rate different from chance (i.e. responded systematically to the incidental point) (see Figure 2). ${ }^{5}$ Surprisingly, the analysis identified no main effects for Group or RLA, nor an interaction. Regression analyses showed no effect of CA for the TD and ID groups but unexpectedly a higher CA was indicative of fast mapping (incorrectly) for the children with ASC (intercept $=.55$, Beta $=.38,\left(F(1,25)=4.531, p<.05, \mathrm{R}^{2}=.11\right)$.

\subsection{Hypothesis 3: Effect of spatio-temporal position}

As there was only a single trial of each type within each cue, the gaze, referential pointing and gaze + pointing trial types were collapsed (the 'pointing incidental' trials were omitted because there was no 'correct' answer here, with the TD and ID groups expected to perform at chance). The $t$-tests (see Table 3) showed above chance performance for all three groups for the same position trials $(p<.005)$ and for TD and ASC children (both $p<.001)$ for the reversed trials, although the ID children were at chance $(t(25)=1.51, p=.13)$. We conducted a GLM with Group as a factor, RLA as a continuous covariate and Object Position (same vs. reversed) as a repeated measure. This revealed an effect of Object Position $(F(1$, 72) $\left.=7.69, p=.007, \eta p^{2}=.1\right)$. Children were more successful at trials where the objects remained in the same position than when the location of the objects reversed. There was also a main effect of $\operatorname{Group}\left(F(2,72)=4.59, p=.01, \eta p^{2}=.1\right)$, with ID children performing worse than TD (Tukey $p=.009$ ) and ASC children (Tukey $p=.02$ ), and no interaction.

\footnotetext{
${ }^{5}$ As participants conducted 8 consecutive, but randomized, trials performance on one trial may have carried over to the next. Specifically, participants who had previously seen gaze and pointing used referentially may have been likely to have also assumed referential intent from incidental pointing. However, re-running the analyses using only participants who viewed the incidental pointing trials first produced results consistent with the findings overall; both TD children $(p=.001)$ and children with ASC $(p=.033)$ selected the object suggested by the incidental pointing and children with ID showed a trend towards doing so $(p=.058)$. Therefore, we can discount possible carry-over effects.
} 


\section{Discussion}

This study investigated gaze and pointing across typical and atypical development. With regards to our three initial hypotheses: 1 . As expected, fast mapping using gaze as a cue was positively related to CA and RLA for children with ASC. RLA was positively related to fast mapping from gaze + pointing for all three groups. There was no effect of CA or RLA for referential pointing. 2. Children with ASC formed word-object mappings from both referential and incidental pointing but, surprisingly, the two comparison groups did too. 3 . Unexpectedly, only children with ID were at chance on the reversed position trials. We discuss these findings in turn.

Crucially, the children with ASC (mean RLA of 5.74) fast mapped from both gaze and pointing. These findings are consistent with Akechi et al. (2011) and Norbury et al., (2010) who found that children with ASC fast map using gaze; the respective RLA's of their participants were seven and nine years. Importantly, however, Luyster and Lord's (2009) finding that 30-month-old children with ASC fast map from gaze suggests that this ability might develop in even younger children than those studied here. One key distinction in their study is that they labelled the target word 9 times. It is possible that additional input cementing word-object relations provides children the opportunity to notice gaze and explore the object in the experimenter's focus of attention.

Although children with ASC fast mapped from gaze and pointing, we found developmental differences in their use of gaze, as there was positive relation with CA. Older children with ASC may have increased experience with word learning interventions that concentrate specifically on joint attention (Mundy, 2016: chapter 5; Prizant, Wetherby, Rubin, Laurent, \& Rydell, 2006), which further research should explore. Children with ASC may also develop alternate strategies over time, such as learning to focus more on gaze (Wing 
\& Gould, 1979) with experience and / or 'hacking' solutions to problems (Frith, Morton \& Leslie, 1991; Happé, 1995) in contrast to TD children's intuitive reasoning, which might be more unconscious (Frith et al., 1991).

As predicted, the participants with ID fast mapped from gaze. There was no effect of CA or RLA on their performance. However, these children failed to fast map from referential pointing, choosing at chance between the target object and distractor and performing significantly worse than the TD children and the children with ASC. The children with ID's elevated scores for the CARS and SCQ compared with TD participants suggest some social difficulties (see Table 1), although they were still well below the clinical cut-off point for suggested ASC. Indeed, some previous findings suggest that children with ID understand pointing better than children with ASC (Landry \& Loveland, 1988; Loveland \& Landry, 1986), contradicting the results of this study. However, other studies propose a limited understanding of social cues in infants at risk for ID (Arens et al., 2005) and that children with moderate learning difficulties may be more impaired than children with ASC learning words in some contexts (Franken, Lewis \& Malone, 2010). Furthermore, only a minority (3/27) of our participants with ASC also had ID, whereas typically around half of an ASC sample have comorbid ID (Charman, Pickles, Simonoff, Chandler, Loucas \& Baird, 2011). This may have contributed to our sample of children with ASC performing better than the children with ID in some analyses.

When gaze and pointing were coupled, the performance of the children with ASC matched the TD group. The children with ID were above chance for this cue but less accurate than the other two groups. Akechi et al. (2013) showed that pointing alongside gazing increased word-object mapping in ASC, compared with gazing alone. They left open the question of whether pointing increases the salience of the speaker's referential intent or whether children with ASC home in on the point, to the exclusion of gaze. Our analysis measured referential pointing when the actor gazed into the camera, therefore providing no gaze information and a direct test of these hypotheses. Children with ASC used pointing 
REFERENT SELECTION IN ASC AND ID

decoupled from gaze. The open question is whether children with ASC learn the social

significance of pointing, like gaze, over time or are attuned to it early on. 
Regarding our second hypothesis; against our predictions, all three groups of children fast mapped for incidental pointing. Recall that participants were expected to perform at chance here, if they understood referential intent. It is possible that in our procedure children (including those with ASC) noticed the pragmatic cues of a point, even when the speaker looked away. The scene was plain and the speaker gazed to one side. The only cue was the point and, given this action and the sparseness of the visual scene, it may have been more obvious than in similar investigations with less marked pointing. In the 'distracted point' procedure used by Behne et al., (2005) the gesture was part of a rich interaction in which the experimenter both hid an object and 'looked down at her hand. Her facial expression suggested that she was preoccupied with inspecting her hand or wrist watch' (page 497). That in the Behne study (2005) toddlers did not respond to the point but here a sample with a higher RLA did, suggests that further research needs to specify the conditions under which children use a pragmatic cue. This might provide crucial information about typical and atypical patterns of acquisition of pragmatic and word learning skills.

Consistent with more pragmatic accounts of pointing (Tomasello et al., 2007), in the absence of any other cue, children may have assumed that the actor intended to refer to the object the speaker pointed towards. However, we did not use a measure of intention monitoring skills so whether older children also possessed greater intention reading ability cannot be empirically validated. Alternatively, both pointing and gaze could prompt learning through association (McMurray et al., 2012; Samuelson \& Smith, 1998). Older children with ASC may have more experience honing in on points if they have received feedback that this is a reliable strategy, especially when faced with uncertainty interpreting gaze. Further studies should present children with a range of pragmatic vs. associative cues to tease apart these alternative hypotheses. Nevertheless, this study shows that across conditions children with ASC appear to respond similarly to a range of cues as TD children. 
Our third hypothesis considered fast mapping when the target object changes location; in the real world, referents seldom remain static. Contrary to our predictions, children with ASC were successful at referent selection in both same and reversed position trials, suggesting they form word-to-object, rather than word-to-location mappings. This suggests that low-level associations may not underlie the first stages of word learning, specifically, referent selection (McMurray et al., 2012) for children with ASC. However, children with ID were unable to form word-object mappings from the reversed position trials, implying that they might focus on lower-level perceptual characteristics for naming. Children with ID often have memory (Jarrold, Baddeley \& Philips, 2007) and cognitive (Edgin, 2013) deficits, leading to difficulties maintaining the mapping across spatial temporal location. Future research should explore the role of spatio-temporal position on referent selection across atypical development.

Several factors may contribute to the children with ID's difficulty using social cues for referent selection. Slow processing speed occurs in children with various difficulties (Burden, Jacobson \& Jacobson, 2005; Miller, Kail, Leonard \& Tomblin, 2001; Silverman, 2007). Participants with ID might have spent a long time trying to understand the visual scene, which moved on too quickly for them to perceive fully. This may have particularly affected referential pointing trials where the speaker looked directly ahead while pointing, which is contextually odd. If the children with ID fixated on the speaker's face, expecting him to look at the object as he spoke, they may not have noticed his pointing. Future studies should include processing speed measures to address these questions. Children with ID may also find it difficult to understand two simultaneous cues (Kovattana \& Kraemer, 1974), making the coupled condition particularly challenging.

Furthermore, the participants with ID were very heterogeneous in terms of their disorder. Children with different conditions sometimes show diverse performance in tasks 
involving understanding social cues (John \& Mervis, 2010). A deficit in understanding pointing may not be universal in ID children but may have simply occurred as an artefact of including children with various conditions here. Thus, specific cohorts should be compared in future research (e.g. a whole group of children with Down Syndrome).

We acknowledge that this study has several limitations. The artificial design, with the child viewing the cues via video in a quiet room with just the experimenter, is quite different from the usual word learning context, where children view speaker's gazing and pointing in 'real time' and frequently surrounded by various distractions. Crucially, children with ASC often have sensory processing difficulties (e.g. Fernandez-Andres, Pastor-Cerezuela, SanzCervera \& Tarraga-Minguez, 2015) which might mean that they struggle to learn words in their daily environment, despite their success here. The TD group was also only matched on RLA and not CA to the ASC and ID children; future ASC research should aim to recruit both RLA and CA matched TD children.

Despite these limitations, taken together, the results of this study suggest that children with ASC fast map from social pragmatic cues. This supports various past studies (e.g. Akechi et al., 2011; 2013; Ellawadi \& McGregor, 2016; McGregor et al., 2013; Norbury, et al., 2010) and indicates that children with ASC attend to a speaker's gaze and pointing and understand that novel words likely refer to the object being gazed at and/or pointed towards. Furthermore, children with ASC formed word-to-object mappings, rather than word-tolocation mappings. This is useful in their daily life; for example, a ball remains a ball whether it is in a shop, the child's toy box or the garden.

Individuals working with children who have ASC (e.g. parents, teachers and other professionals) should note that some of these individuals engage in joint attention and fast map from social pragmatics, particularly older children. Future studies should utilise a broad CA and RLA of children in order to pinpoint the developmental time point at which these 
abilities develop in ASC. These findings also highlight for researchers and other professionals the difficulties children with ID may experience understanding social pragmatic cues. If replicated and extended, the findings would indicate that several of the problems of ASC are not simply a feature of their associated intellectual impairments and that, indeed, the processing skills of children with ID may be delayed. The three groups studied here suggest differential access to these social cues depending upon clinical diagnosis and language development.

\section{Acknowledgements}

Thanks to children, parents and teachers, Calum Hartley for acting as the speaker and Dave Gaskell and Barrie Usherwood for help preparing stimuli.

This work was carried out as part of the first author's doctoral research, funded by X University.

\section{Declarations of Interest: None.}

\section{References}

Akechi, H., Senju, A., Kikuchi, Y., Tojo, Y., Osanai, H., Hasegawa, T. (2011). Do children with ASD use referential gaze to learn the name of an object? An eye tracking study. Research in Autism Spectrum Disorders, 5, 1230-1242.

Akechi, H., Kikuchi, Y., Tojo, Y., Osanai, H., \& Hasegawa, T. (2013). Brief report: Pointing cues facilitate word learning in children with autism spectrum disorder. Journal of Autism and Developmental Disorders, 43, 230-235.

Allen, M. A., Hartley, C., \& Cain, K. (2015). Do i-Pads promote symbolic understanding and word learning in children with autism? Frontiers in Psychology, 6, 138. 
Arens, K., Cress, C. J., \& Marvin, C. A. (2005). Gaze-shift patterns of young children with developmental disabilities who are at risk for being nonspeaking. Education and Training in Developmental Disabilities, 40, 158-170.

Bani Hani, H., Gonzalez Barrero, A. M., \& Nadig, A. S. (2012). Children's referential Understanding of novel words and parent labelling behaviours: Similarities across children with and without autism spectrum disorders. Journal of Child Language, 40, $1-32$.

Baldwin, D. A. (1991). Infants' contribution to the achievement of joint reference. Journal of Child Development, 62, 875-890.

Baldwin, D. A. (1993). Infants' ability to consult the speaker for clues to word reference. Journal of Child Language, 20, 395-418.

Baron-Cohen, S. (1989). Perceptual role-taking and protodeclarative pointing in autism. British Journal of Developmental Psychology, 7, 113-127.

Baron-Cohen, S., Baldwin, D. A., \& Crowson, M. (1997). Do children with autism use the speaker's direction of gaze strategy to crack the code of language? Journal of Child Development, 68, 48-57.

Baron-Cohen S (2000). Is Asperger syndrome/high-functioning autism necessarily a disability? Development and Psychopathology, 12, 489-500

Behne, T., Carpenter, M., \& Tomasello, M. (2005). One-year-olds comprehend the communicative intentions behind gestures in a hiding game. Developmental Science, 8, 492-499.

Beier, J. S., \& Spelke, E. S. (2012). Infants' developing understanding of social gaze. Child Development, 83, 486-496.

Benitez, V. I., \& Smith, L. B. (2012). Predictable locations aid early name learning. Cognition, 125, 339-352. 
Bloom, P. (2000). How children learn the meanings of words. Cambridge, MA: MIT Press.

Brereton, A. V., Tonge, B. J., \& Einfeld, S. L. (2006). Psychopathology in Children and Adolescents with Autism Compared to Young People with Intellectual Disability. Journal of Autism and Developmental Disorders, 36, 863-870.

Burden, M. J., Jacobson, S. W., \& Jacobson, J. L. (2005). Relation of prenatal alcohol exposure to cognitive processing speed and efficiency in childhood. Alcoholism: Clinical and Experimental Research, 29, 1473-1483.

Camaioni, L., Perucchini, P., Muratori, F., \& Milone, A. (1997). Brief Report: A Longitudinal Examination of the Communicative Gestures Deficit in Young Children with Autism. Journal of Autism and Developmental Disorders, 27, 715-725.

Canfield, R. L., \& Haith, M. M. (1991). Young children's visual expectations for symmetrical and asymmetric stimulus sequences. Developmental Psychology, 27, 198-208.

Capone, N. C., \& McGregor, K. (2005). The effect of semantic representation on toddlers' word retrieval. Journal of Speech, Language and Hearing Research, 48, 1468-1480.

Charman, T. Pickles, A., Simonoff, E., Chandler, S., Loucas, T., \& Baird, G. (2011). IQ in children with autism spectrum disorders: Data from the Special Needs and Autism Project (SNAP). Psychological Medicine, 41, 619-627.

Congiu, S., Fadda, R., Doneddu, G., \& Striano, T. (2016). Impaired representational gaze following in children with autism spectrum disorder. Research in Developmental Disabilities, 57, 11-17.

D’Entremont, B., \& Yazbek, Y. (2007). Imitation of intentional and accidental actions by children with autism. Journal of Autism and Developmental Disorders, 37, 1665-78.

Dunn, L. M., Dunn, L. M., Whetton, C., \& Burley, J. (1997). The British Picture Vocabulary Scale (Second Edition). Great Britain: National Foundation for Educational Research. 
Edgin, J. O. (2013). Cognition in Down Syndrome: A Developmental Cognitive Neuroscience Perspective, Wiley Interdiscirplinary Reviews, Cognitive Science, 4, 307-317.

Ellawadi, A. B., \& McGregor, K. M. (2016). Children with ASD can use gaze to map new words. International Journal of Language and Communication Disorders, 51, 212218.

Falck-Ytter, T., Fernell, E., Hedvall A., von Hofsten C., \& Gillberg, C. (2012). Gaze performance in children with autism spectrum disorder when observing communicative actions. Journal of Autism and Developmental Disorders, 42, 22362245

Fernandez-Andres, M. I., Pastor-Cerezuela, G., Sanz-Cervera, P. \& Tarraga-Minguez, R. (2015). A comparative study of sensory processing in children with and without Autism Spectrum Disorder in the home and classroom environments. Research in Developmental Disabilities, 38, 202-212.

Franken, T. Lewis, C., \& Malone, S. (2010). Are children with autism proficient word learners? Journal of Autism and Developmental Disorders, 40, 255259.

Frith, U., Morton, J., \& Leslie, A. M. (1991). The cognitive basis of a biological disorder: Autism. Trends in Neurosciences, 14, 433-438.

Gillespie-Smith, K., Doherty-Sneddon, G., Hancock, P. J. B., \& Riby, D. (2014). That looks familiar: Attention allocation to familiar and unfamiliar faces in children with autism spectrum disorder. Cognitive Neuropsychiatry, 19, 554-569

Gillespie-Smith, K., Riby, D., Hancock, P. J. B., \& Doherty-Sneddon, G. (2014). Children 
with Autism Spectrum Disorder (ASD) attend typically to faces and objects presented within their picture communication systems. Journal of Intellectual Disability Research, 58, 459-470.

Gliga, T., \& Csibra, G. (2009). One-year-old infants appreciate the referential nature of deictic gestures and words. Psychological Science, 20, 347-353.

Griffin, Z. M., \& Bock, K. (2000). What the eyes say about speaking. Psychological Science, 11, $274-279$

Happè, F. G. E. (1995). The role of age and verbal ability in the theory of mind task performance of subjects with autism. Child Development, 66, 843-855.

Hartley, C., \& Allen, M. L. (2014). Generalisation of word-picture relations in children with autism and typically developing children. Journal of Autism and Developmental Disorders, 44, 2064-2071.

Hartley, C., \& Fisher, S. (2018). Do children with autism spectrum disorder share fairly and Reciprocally? Journal of Autism and Developmental Disorders, 48, 2714-2726.

Hayashi, M., Kato, M., Igarashi, K., \& Kashima, H. (2007). Superior fluid intelligence in children with Asperger's Disorder. Brain and Cognition, 66, 306-10.

Hobson, R. P., \& Meyer, J. A. (2005). Foundations for self and other: A study in autism. Developmental Science, 8, 481-91.

Hollich, G., Hirsh-Pasek, K., Golinkoff, R.M., Brand, R. J., Brown, E., Chung, H. L., Hennon, E., Rocroi, C. (2000). Breaking the language barrier: An emergentist coalition model of word learning. Monograms of the Society of Research in Child Development, 65, 3

Horst, J. S., McMurray, B., \& Samuelson, L. K. (2006). Online processing is essential for learning: Understanding fast mapping and word learning in a dynamic connectionist architecture. Proc. of CogSci'06.

Horst, J. S., Scott, E. J., \& Pollard, J. A. (2010). The role of competition in word learning via referent selection. Developmental Science, 13, 706-713. 
Jarrold C, Baddeley A. D, \& Phillips C. (2007). Long-term memory for verbal and visual information in Down syndrome and Williams syndrome: Performance on the Doors and People test. Cortex. 43, 233-247

John, A. E., \& Mervis, C. B. (2010). Comprehension of the communicative intent behind pointing and gazing gestures by young children with Williams Syndrome. Journal of Speech, Language and Hearing Research, 53, 950-960.

Jones, W., Carr, K., \& Klin, A. (2008). Absence of preferential looking to the eyes of approaching adults predicts level of social desirability in 2-year-old toddlers with autism spectrum disorder. Arch Gen Psychiatry, 65, 946-54.

Johnson, M. H., \& Tucker, L. A. (1996). The development and temporal dynamics of spatial orienting in infants. Journal of Experimental Child Psychology, 63, 171-188.

Kalagher, H., \& Yu, C. (2006). The effects of deictic pointing in word learning. Proceedings of the 5th International Conference of Development and Learning

Kenny et al (2015). Which terms should be used to describe autism? Perspectives from the UK autism community. Autism, 20, 442-462.

Keppel, G., \& Wickens, T. D. (2004). Design and Analysis, a Researcher's Handbook. New Jersey: Pearson Prentice-Hall.

Kovattana, P. M., \& Kraemer, H. C. (1974). Response to multiple visual cues of color, size, and form by autistic children. Journal of Autism and Childhood Schizophrenia, 4(3), 251-261.

Krehm, M., Onishi, K. H., \& Vouloumanos, A. (2014). I see your point: Infants under 12 months understand that pointing is communicative. Journal of Cognition and Development, 15 , 527-538.

Landry, S. H., \& Loveland, K. A. (1988). Communication behaviors in autism and 
developmental language delay. Journal of Child Psychology and Psychiatry, 29, 621634.

Lord, C., Rutter, M., DiLavore, P. C., \& Risi, S. (2002). Autism Diagnostic Observation Schedule (WPS edition). Los Angeles: Western Psychological Services.

Lord, C., Rutter, M., \& Le Couteur, A. (1994). Autism Diagnostic Interview - Revised: A revised version of a diagnostic interview for caregivers of individuals with possible pervasive developmental disorders. Journal of Autism and Developmental Disorders, 24, 659-685.

Loveland, K., \& Landry, S. (1986). Joint attention and language in autism and developmental language delay. Journal of Autism and Developmental Disorders, 16, 335-349.

Luyster, R., \& Lord, C. (2009). Word learning in children with autism spectrum disorders. Developmental Psychology, 45, 1774-1786.

Marrus, N., \& Hall, L. (2017). Intellectual Disability and Language Disorder. Child and Adolescent Psychiatric Clinic of North America, 26, 539-554.

Mcduffie, A., S., Yoder, P. J., \& Stone, W. L., (2006). Labels increase attention to novel objects in children with autism and comprehension-matched children with typical development. Autism, 10, 288-301

McDufffie, A., Kover, S. T., Hagerman, R., \& Abbeduto, L. (2013). Investigating word learning in Fragile X Syndrome: A fast mapping study. Journal of Autism and Developmental Disorders, 43, 1676-1691.

McDuffie, A., Sindberg, H. A., Hesketh, L. J., \& Chapman, R. S. (2007). Use of Speaker Intent and Grammatical Cues in fast-mapping by adolescents with Down Syndrome. Journal of Speech, Language and Hearing Research, 50, 1546-61.

McGregor, K. K., Rost, G., Arenas, R., Farris-Trimble, A., \& Stiles, D. (2013). Children 
with ASD can use gaze in support of word recognition and learning. Journal of Child Psychology and Psychiatry, 54, 745-75.

McMurray, B., Horst, J. S., \& Samuelson, L. K. (2012). Word learning emerges from the interaction of online referent selection and slow associative learning. Psychological Review, 119, 831-877.

Miller, C. A., Kail, R., Leonard, L. B., \& Tomblin, J. B. (2001). Speed of processing in children with specific language impairment. Journal of Speech, Language and Hearing Research, 44, 416-33.

Moog, U. (2005). The outcome of diagnostic studies on the etiology of mental retardation: Considerations on the classification of the causes. American Journal of Medical Genetics, 2, 228-231.

Moore, C. (1999). Intentional relations and triadic relations. In P. D. Zelazo, J. W. Astington, \& D. R. Olson (Eds.), Developing theories of intention. Mahwah, NJ: Lawrence Erlbaum Associates.

Mundy, P. (1995). Joint attention and social-emotional approach behavior in children with autism. Development and Psychopathology, 7, 63-82.

Mundy, P. (2016). Autism and Joint Attention: Development, Neuroscience, and Clinical Fundamentals. New York: Guilford Publications.

Mundy, P., Sigman, M., \& Kasari, C. (1994). Joint attention, developmental level and symptom presentation in autism. Development and Psychopathology, 6, 389-401.

Norbury, C. F., Griffiths, H., Nation, K. (2010). Sound before meaning: Word learning in autistic disorders. Neuropsychologia, 48, 4012-4019. 
Parish-Morris, J., Hennon, E. A., Hirsh-Pasek, K., Golinkoff, R. M., \& Tager-Flusberg, H. (2007). Children with autism illuminate the role of social intention in word learning. Child Development, 78, 1265-1287.

Porter, M. A., \& Coltheart, M. (2006). Global and local processing in Williams syndrome, autism, and Down syndrome: perception, attention, and construction. Developmental Neuropsychology, 30(3), 771-789.

Preissler, M. A., \& Carey, S. (2005). The role of inferences about referential intent in word learning: Evidence from autism. Cognition, 97, 13-23.

Prizant, B. M., Wetherby, A. M., Rubin, E., Laurent, A. C., \& Rydell, P. J. (2006). The SCERTS model. A comprehensive educational approach for children with autism spectrum disorders. Program planning and intervention. Baltimore: Paul H. Brookes.

Ratner, R.B. (2005). Atypical language development. In J.B. Gleason (Ed.) The development of language. 6th ed. Boston: Pearson.

Raven, J. C. (2003). Raven's Coloured Progressive Matrices. Oxford: Information Press.

Riby, D., Hancock, P. J. B., Jones, N., \& Hanley, M. (2013). Spontaneous and cued gazefollowing in autism and Williams syndrome. Journal of Neurodevelopmental Disorders, 5, 13.

Riguet, C. B., Taylor, N. D., Benaroya, S., \& Klein, L. S. (1984). Symbolic play in Autistic, Down's and normal children of equivalent mental age. Journal of Autism and Developmental Disorders, 11, 439-448.

Rosenberg, S., \& Abbeduto, L. (1993). Language and Communication in Mental Retardation: Development, Process, and Intervention. Hillsdale, NJ: Lawrence Erlbaum Associates.

Rutter, M., Bailey, A., Berument, S. K., Lord, C., \& Pickles, A. (2003). Social 
Communication Questionnaire (SCQ). Los Angeles, CA: Western Psychological Services.

Sakhon, S., Edwards, K., Luongo, A., Murphy, M., \& Edgin, J. (2018). Small sets of novel words are fully retained after 1-week in children with and without Down syndrome: A fast mapping study, J Int Neuropsychol Soc., 24, 955-965.

Sally, D., \& Hill, E. (2006). The development of interpersonal strategy: Autism, theory-ofmind, cooperation and fairness. Journal of Economic Psychology, 27, 73-97.

Samuelson, L. K., \& Smith, L. B. (1998). Memory and attention make smart word learning: An alternative account of Akhtar, Carpenter, and Tomasello. Child Development, 69, 94-104.

Schopler, E., Reichler, R., \& Rochen Renner, B. (1988). The Childhood Autism Rating Scale (CARS). Los Angeles, CA: Western Psychological Services.

Silverman, W. (2007). Down Syndrome: Cognitive Phenotype. Mental Retardation and Developmental Disabilities Research Reviews, 13, 228-236.

Somogyi, E., Kiraly, I., Gergely, G., \& Nadel, J. (2013). Understanding goals and intentions in low-functioning autism. Research in Developmental Disabilities, 34, 3822-3833.

Soulières, ... \& Mottron, (2009). Enhanced visual processing contributes to matrix reasoning in autism. Human Brain Mapping, 30, 4082-4107.

Stone, W. L., Ousley, O. Y., Yoder, P. J., Hogan, K. L., \& Hepburn, S. L. (1997). Nonverbal communication in two-and three-year-old children with autism. Journal of Autism and Developmental Disorders, 27, 677-696.

Tomasello, M. (1995). Joint attention as social cognition. (pp 103-130). In C. Moore \& P. J. Dunham (Eds) Joint attention: Its origins and role in development. Hove: Psychology Press.

Tomasello, M., Carpenter, M., \& Liszkowski, U. (2007). A new look at infant pointing. Child Development, 78, 705-722.

Travis, L. T., \& Sigman, M. (2001). Communicative intentions and symbols in autism: 
Examining a case of altered development. In J. A. Burack, T. Charman, N. Yirmiya \& P.R. Zelazo (eds.) The development of autism (pp. 279-308). New Jersey: Lawrence Erlbaum Associates.

Wilkins, J., \& Matson, J. L. (2009). A comparison of social skills profiles in intellectually disabled adults with and without ASD. Behaviour Modification, 33, 143-155.

Wilkinson, K. (2007). Effect of "missing", information on fast-mapping of individuals with vocabulary limitations associated with intellectual disability. American Journal on Mental Retardation, 112, 40-53

Wing, L., \& Gould, J. (1979). Severe impairments of social interaction and associated abnormalities in children: Epidemiology and classification. Journal of Autism and Developmental Disorders, 9, 11-29.

Woodward, A. L. (1998). Infants selectively encode the goal object of an actor's reach. Cognition, 69, 1-34.

Woodward, A. L., \& Guajardo, J. J. (2002). Infants' understanding of the point gesture as an object-directed action. Cognitive Development, 17, 1061-1084.

Yale, M. E., \& Mundy, P. (1998). Infant gaze direction during a novel labelling task. Infant Behavior and Development, 21, 771. 
Table 1 Participant details

\begin{tabular}{lcll}
\hline & $\boldsymbol{T D}(\boldsymbol{N}=\mathbf{3 0})$ & $\boldsymbol{A S C}(\boldsymbol{N}=\mathbf{2 7})$ & $\boldsymbol{I D}(\boldsymbol{N}=\mathbf{2 1})$ \\
\hline Mean CA (SD) & $4.15(1.28)$ & $9.93(2.39)$ & $8.61(2.00)$ \\
Mean RLA (SD) & $4.74(1.58)$ & $5.74(1.91)$ & $4.98(1.56)$ \\
Mean Raven's score (SD) & $12.87(5.82)$ & $19.08(8.21)$ & $12.85(7.53)$ \\
Mean CARS score (SD) & $15.15(.49)$ & $34.55(6.33)$ & $23.29(4.74)$ \\
Mean SCQ score (SD) & $2.76(1.75)$ & $15.72(5.27)$ & $8.87(5.63)$ \\
\hline
\end{tabular}


Table 2: Study Procedure

\begin{tabular}{|c|c|c|c|c|}
\hline \multicolumn{5}{|c|}{ TIMING OF VIDEO } \\
\hline O seconds & \multicolumn{4}{|c|}{ Speaker looks directly ahead, with arms by his side } \\
\hline 3 seconds & \multicolumn{4}{|c|}{$\begin{array}{l}\text { Speaker utters 'There's a modi(fep/peri/zav/toma/riff/tog/neem)... it's a } \\
\text { modi'. }\end{array}$} \\
\hline 6 seconds & \multicolumn{4}{|c|}{ Objects in isolation appear on the screen and test trial commences } \\
\hline \multicolumn{5}{|c|}{ CUE TYPES } \\
\hline & $\begin{array}{l}\quad \text { GAZE } \\
\text { Speaker directs } \\
\text { his gaze } \\
\text { towards the } \\
\text { target object }\end{array}$ & $\begin{array}{l}\text { REFERENTIAL } \\
\quad \text { POINTING } \\
\text { Speaker points at } \\
\text { the target, } \\
\text { keeping gaze } \\
\text { directed straight } \\
\text { ahead }\end{array}$ & $\begin{array}{l}\text { INCIDENTAL } \\
\text { POINTING } \\
\text { Speaker points } \\
\text { at the target, } \\
\text { looking off into } \\
\text { the distance in } \\
\text { the opposite } \\
\text { direction of the } \\
\text { point, as though } \\
\text { momentarily } \\
\text { distracted }\end{array}$ & $\begin{array}{l}\quad \text { GAZE + } \\
\text { POINTING } \\
\text { Speaker directs } \\
\text { both gaze and } \\
\text { pointing } \\
\text { towards the } \\
\text { target }\end{array}$ \\
\hline
\end{tabular}


Table 3: Mean proportion (SD) of children choosing target object for the same and reversed position trials and one-sample t-tests against chance performance

\begin{tabular}{cccc}
\hline & TD & ASC & ID \\
Same Position & $.90(.20) * * *$ & $.90(.18) * * *$ & $.74(.35) *$ \\
$t$-test & $t(29)=10.88$ & $t(26)=11.35$ & $t(20)=3.21$ \\
Reversed Position & $p<.001, d=2.00$ & $p<.001, d=2.22$ & $p=.004, d=.69$ \\
$t$-test & $.83(.23) * * *$ & $.79(.27) * * *$ & $.61(.31)$ \\
& $t(29)=7.89$ & $t(26)=5.61$ & $t(20)=1.59$ \\
& $p<.001, d=1.43$ & $p<.001, d=1.07$ & $p=.13$ \\
\hline
\end{tabular}


Click here to download high resolution image

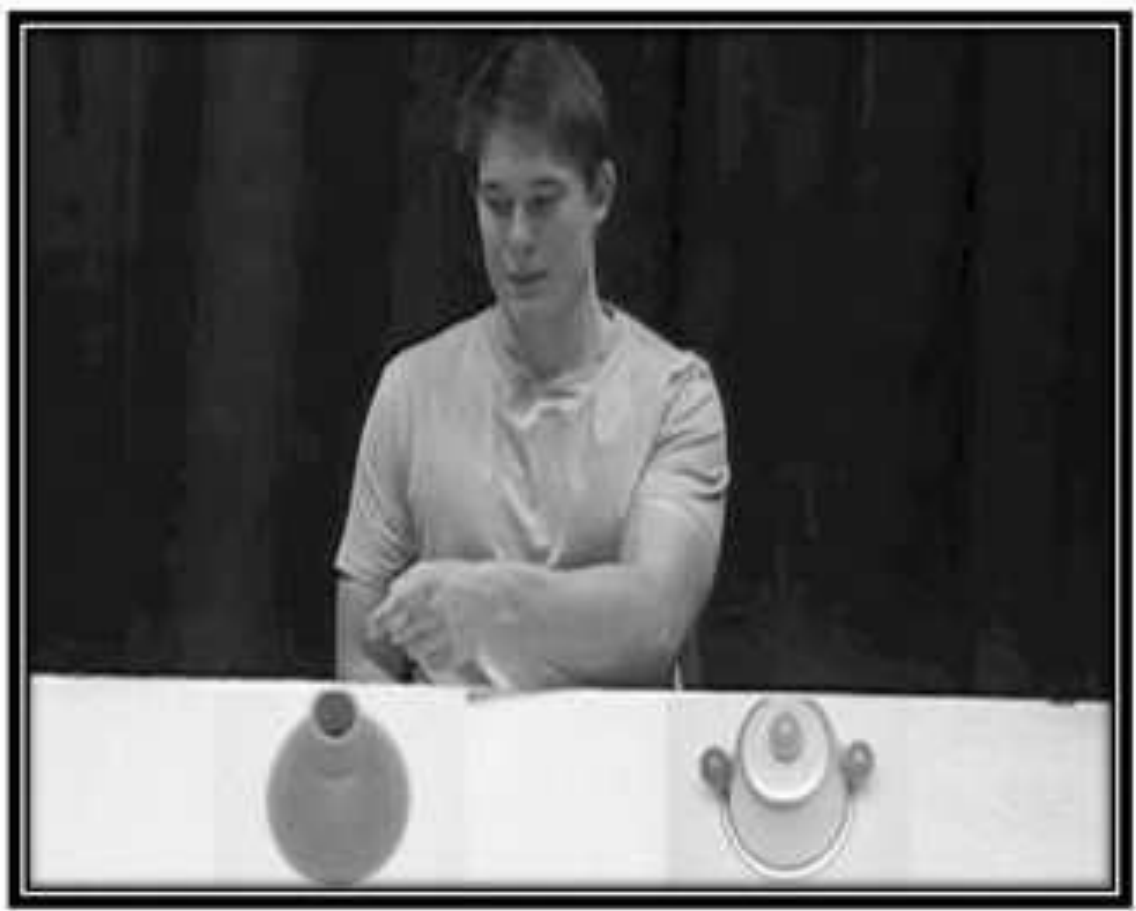

Figure I: Example image of an eye gaze + pointing trial 
Figure

Click here to download high resolution image

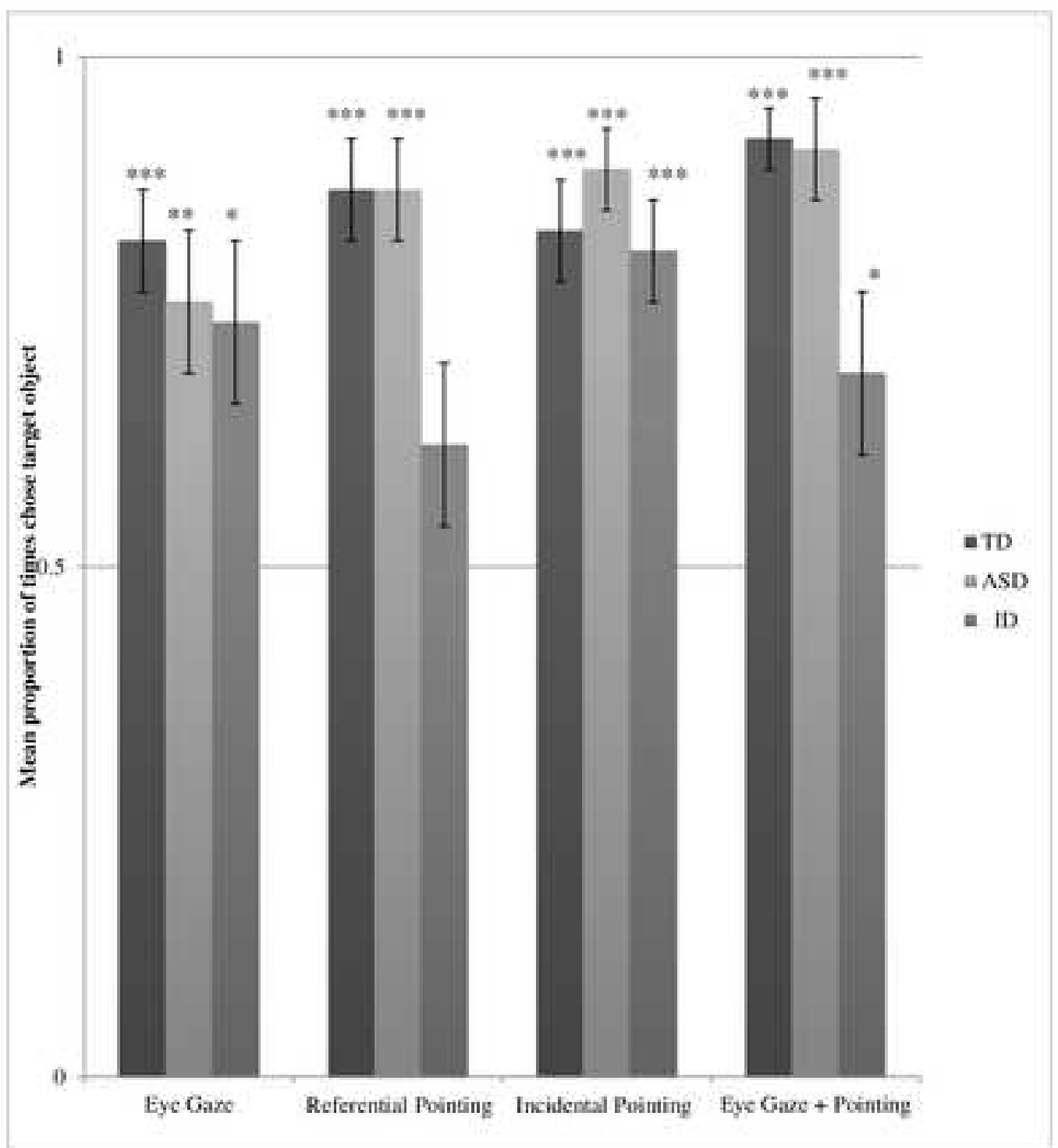

Figure 2: Mean proportion of times childnen chose the target object fasterisks above barx denotes above chance performance on these trials in each group).

$" p<05 * 0<0.01 *+1 p<.001$. 
Referent selection in children with Autism Spectrum Condition and Intellectual Disabilities:

Do social cues affect word-to-object or word-to-location mappings?

Charlotte Field ${ }^{1}$ (cfield2@uclan.ac.uk), Charlie Lewis (c.lewis@lancaster.ac.uk) \& Melissa

$$
\text { L. Allen (melissa.allen@ bristol.ac.uk) }{ }^{2}
$$

Lancaster University, Fylde College, Department of Psychology, Lancaster, LA1 4YF, United Kingdom

Corresponding Author:

Charlotte Field

Email: cfield2@uclan.ac.uk

Telephone: +441772893446

Fax: +441772892925

\footnotetext{
${ }^{1}$ Present address, to send correspondence concerning the manuscript: The University of Central Lancashire, Darwin Building, School of Psychology, Preston, Lancashire, UK, PR12HE

${ }^{2}$ Present address: School of Education, University of Bristol, Helen Wodehouse Building, 35 Berkeley Square, Clifton, Bristol, BS8 1JA
} 